Article

\title{
One-Step Synthesis of Silver Nanoparticles on Polydopamine-Coated Sericin/Polyvinyl Alcohol Composite Films for Potential Antimicrobial Applications
}

\author{
Rui Cai ${ }^{1}$, Gang Tao ${ }^{2}$, Huawei He ${ }^{2}$, Kai Song ${ }^{2}$, Hua Zuo ${ }^{3}$, Wenchao Jiang ${ }^{2}$ and Yejing Wang ${ }^{1, *}$ \\ 1 College of Biotechnology, Southwest University, Beibei, Chongqing 400715, China; \\ cairui0330@email.swu.edu.cn \\ 2 State Key Laboratory of Silkworm Genome Biology, Southwest University, Beibei, Chongqing 400715, China; \\ taogang@email.swu.edu.cn (G.T.); hehuawei@swu.edu.cn (H.H.); \\ 18728301293@163.com (K.S.); jwc1245@163.com (W.J.) \\ 3 College of Pharmaceutical Sciences, Southwest University, Beibei, Chongqing 400715, China; \\ zuohua@swu.edu.cn \\ * Correspondence: yjwang@swu.edu.cn; Tel.: +86-23-68251575
}

Academic Editor: Derek J. McPhee

Received: 25 March 2017; Accepted: 27 April 2017; Published: 30 April 2017

\begin{abstract}
Silk sericin has great potential as a biomaterial for biomedical applications due to its good hydrophilicity, reactivity, and biodegradability. To develop multifunctional sericin materials for potential antibacterial application, a one-step synthesis method for preparing silver nanoparticles (AgNPs) modified on polydopamine-coated sericin/polyvinyl alcohol (PVA) composite films was developed. Polydopamine (PDA) acted as both metal ion chelating and reducing agent to synthesize AgNPs in situ on the sericin/PVA composite film. Scanning electron microscopy and energy dispersive spectroscopy analysis revealed that polydopamine could effectively facilitate the high-density growth of AgNPs as a 3-D matrix. X-ray diffractometry studies suggested the synthesized AgNPs formed good face-centered cubic crystalline structures. Contact angle measurement and mechanical test indicated AgNPs modified PDA-sericin/PVA composite film had good hydrophilicity and mechanical property. The bacterial growth curve and inhibition zone assays showed the AgNPs modified PDA-sericin/PVA composite film had long-term antibacterial activities. This work develops a new method for the preparation of AgNPs modified PDA-sericin/PVA film with good hydrophilicity, mechanical performance and antibacterial activities for the potential antimicrobial application in biomedicine.
\end{abstract}

Keywords: sericin; polyvinyl alcohol; polydopamine; silver nanoparticles; one-step synthesis; antibacterial activity

\section{Introduction}

Silk sericin (SS) is a natural macromolecular protein from silkworm cocoon, which makes up $25 \%$ of the total silk protein [1]. It is produced in the middle silk gland [2]. Sericin protein consists of 18 amino acids, including some essential amino acids [3]. Serine is the main part of human skin natural moisture factor (NMF) [4]. The content of serine in sericin is approximately $33.43 \%$ [5]. Thus, sericin is an excellent moisturizing agent [6]. As an inexpensive, readily available, biodegradable, and biocompatible substance [7-9], sericin has attracted increasing interest in the field of biomaterials. Furthermore, sericin has the mitogenic effect on mammalian cells, which places it in a favorable position for tissue engineering [10,11], especially for the growth and migration of keratinocytes and 
fibroblasts [12,13]. As sericin can promote collagen formation in wounds and thereby accelerate the re-epithelialization of open wounds, sericin has great potential as a wound healing agent [14]. However, sericin has high levels of random coil structures $[15,16]$, which makes it behave like an amorphous material [17] and be fragile in a dry state. Cross-linking, blending, or copolymerization with other substances could overcome the brittleness of sericin [18]. Previously, we blended sericin with polyvinyl alcohol (PVA) to prepare a SS/PVA composite film, which had good hydrophilicity and mechanical properties with potential in wound healing applications. However, silk sericin/polyvinyl alcohol film (SS/PVA) itself lacks antibacterial ability which is not favorable for wound healing because wound infection is an important factor affecting wound healing. There is increasing interest in the development of antifouling or antimicrobial films, which will enhance the application of biological materials [19]. Thus, the development of SS/PVA film with antibacterial ability is required for the application of sericin in the field of wound healing.

Surface immobilization of silver nanoparticles (AgNPs) is a popular method to endow materials with antimicrobial ability because AgNPs have broad-spectrum antimicrobial activities [20-26], low cytotoxicity $[27,28]$ and anti-inflammatory characteristics [29]. AgNPs has a large specific surface area, thereby greatly increasing the probability of AgNPs contact with microbial surfaces. In addition, this rarely leads to the development of resistant microbes. Therefore, AgNP is a very important antibacterial agent [30-32]. In the early stages, AgNPs are pre-synthesized first by some physical or chemical method and then immobilized on the surface of a material via physical or chemical adsorption. Since these procedures are quite complicated and tedious, this strategy has been gradually abandoned [33-35]. As a safe and green method, the use of biomolecules to prepare AgNPs has received more and more attention as it may have a better biocompatibility [36]. However, the biosynthesized AgNPs cannot be directly modified on the surface of the material. Therefore, as an effective alternative, the synthesis of AgNPs in situ on the material surface has been developed. UV irradiation reduction is one of the most convenient methods for the synthesis of AgNPs in situ [37], however, due to the small number of active sites on the SS/PVA film surface, the amounts of AgNPs that can be synthesized on the surface are limited. Various polymers such as polyamide network polymer, poly(vinyl pyrrolidone) and polyacrylic acid have been developed as a 3-dimensional (3D) matrix with a layer-by-layer assembly technique to provide more $\mathrm{Ag}^{+}$binding sites for the high-density growth of AgNPs [38], but the multi-step procedures of this technique are too complicated. Hence, developing a practical one-step synthesis of AgNPs is necessary for antimicrobial surface modification.

Polydopamine (PDA) is a hormone and neurotransmitter in the body [39]. It has strong adsorbability and is environment-friendly, thus it is often used as a versatile platform for secondary reactions after coating on a matrix, which could serve as a carrier to absorb other substances [40]. Based on the self-polymerization of dopamine under weak alkaline conditions, PDA can adhere to almost all material surfaces [41,42]. Since dopamine has metal ion chelating ability and redox activity $[43,44]$, it could directly reduce the adsorbed $\mathrm{Ag}^{+}$on the dopamine-coated material surface to form AgNPs via a one-step reaction $[45,46]$. These properties may facilitate the use of PDA as a 3D matrix to enhance the adsorption of $\mathrm{Ag}^{+}$and promote the high-density growth of AgNPs. In addition, the presence of PDA could avoid direct exposure of AgNPs to oxygen and slow down the release of silver ions. Therefore, a PDA coating on sericin composite films surface might enhance the capacity of AgNPs and produce better antibacterial activity with sericin films.

In this work, we have established a one-step reduction method to prepare AgNPs-modified PDA-SS/PVA films (Figure 1). PDA was coated on the SS/PVA composite film and then used to adsorb and reduce $\mathrm{Ag}^{+}$to form AgNPs. The prepared composite films were characterized by scanning electron microscopy (SEM), energy dispersive spectroscopy (EDS), X-ray diffractometry (XRD) and fourier transfer infrared spectroscopy (FT-IR) to analyze the PDA coating and the synthesis of AgNPs. Antimicrobial assays were conducted to investigate the antimicrobial activity of AgNPs-modified PDA-SS/PVA film against Escherichia coli (E. coli) and Staphylococcus aureus (S. aureus). The AgNPs-modified sericin/PVA composite films exhibited good bactericidal activity and long-lasting 
antimicrobial performance. This prepared AgNPs-PDA-SS/PVA composite film may have potential applications in biomedical materials such as wound dressings.

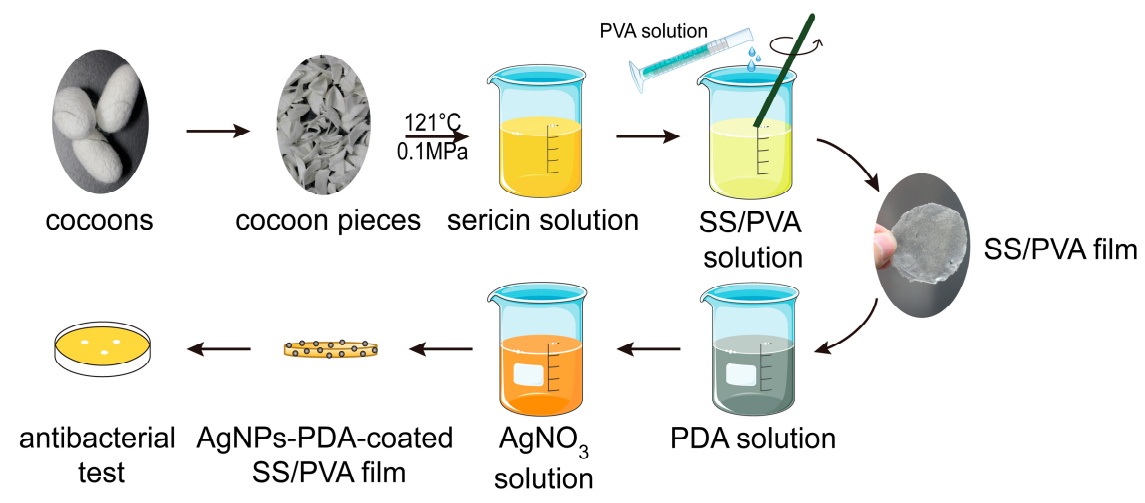

Figure 1. The flow diagram illustrates the preparation and antimicrobial analysis of AgNPs-PDA-SS/PVA composite film.

\section{Results and Discussion}

\subsection{Preparation of PDA Coated SS/PVA Film}

The adsorption of PDA on the film surface is affected by monomer concentration, reaction temperature and time. To determine the best condition for forming a uniform PDA film, SEM experiments were carried out to observe the surface morphologies of SS/PVA film and PDA-coated SS/PVA film prepared with different dopamine concentrations (Figure 2).
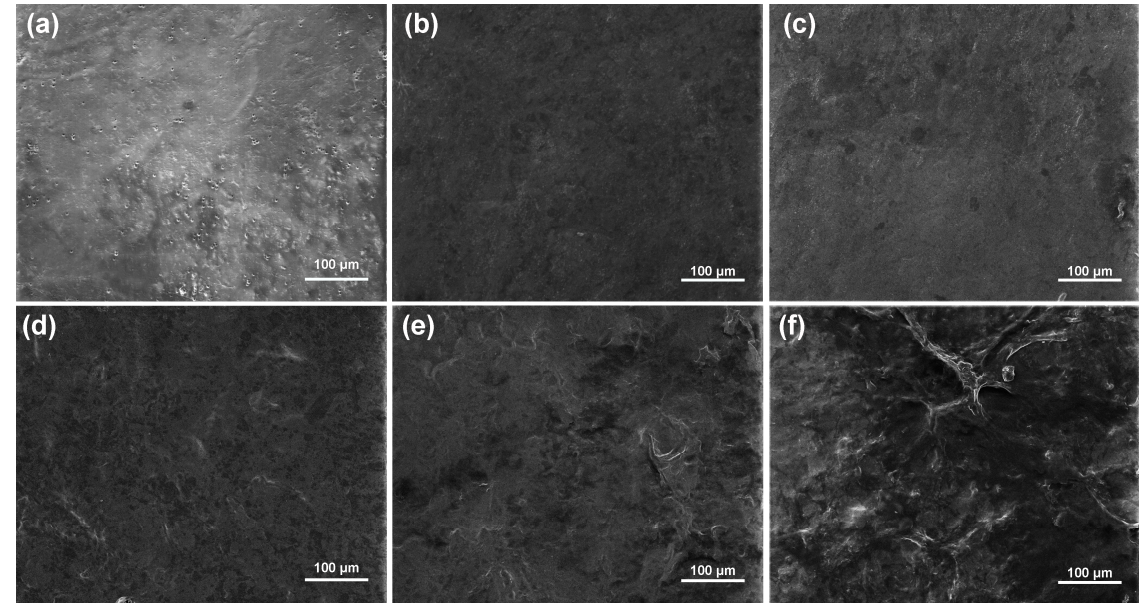

Figure 2. SEM images of SS/PVA film (a) and PDA-coated SS/PVA films prepared with dopamine concentration of $0.5(\mathbf{b}), 1.0(\mathbf{c}), 2.0(\mathbf{d}), 3.0(\mathbf{e})$ and $5.0 \mathrm{mg} / \mathrm{mL}(\mathbf{f})$, respectively.

SS/PVA film had a smooth surface, suggesting the cross-linking of sericin and PVA was successful (Figure 2a). Smooth surfaces with some insignificant tiny dots and pores could be observed on SS/PVA films treated with $0.5-2.0 \mathrm{mg} / \mathrm{mL}$ dopamine solutions (Figure $2 \mathrm{~b}-\mathrm{d}$ )). Rough surfaces with obvious protuberances could be observed on SS/PVA films treated with 3.0 and $5.0 \mathrm{mg} / \mathrm{mL}$ dopamine solution (Figure 2e-f). The results showed that PDA could coat on the composite films with dopamine concentrations as low as $0.5 \mathrm{mg} / \mathrm{mL}$. The degree of PDA adsorption is key for the synthesis and growth of AgNPs. A low concentration of dopamine will form a thin PDA film, which may be not favorable for the high-density growth of AgNPs. However, high concentrations of dopamine will form a thick PDA film, which may affect the flexibility of the material. Hence, the dopamine concentration was 
selected as $2.0 \mathrm{mg} / \mathrm{mL}$, and the surface of PDA-coated SS/PVA film was uniform without obvious protuberances. Besides the concentration of dopamine, reaction temperature and time also affected the adsorption of PDA on the film surface. A previous study shows that high temperature and agitation could speed up the formation of PDA films [47]. Long deposition times could also lead to the formation of a thick PDA film [48]. Thus, in this study, the modification of PDA on the SS/PVA film surface was carried out under constant stirring for $12 \mathrm{~h}$ at room temperature in $2.0 \mathrm{mg} / \mathrm{mL}$ dopamine.

\subsection{FESEM, EDS and XRD Analysis}

Since PDA could adsorb $\mathrm{Ag}^{+}$and catechol moiety of PDA could efficiently reduce $\mathrm{Ag}^{+}$to AgNPs by itself, no additional reagents or treatments are involved in the synthesis of AgNPs. As shown in Figure 3a,b, the surface of the SS/PVA composite films were covered by high-density and uniformly distributed nanoparticles. The size of nanoparticles was mainly in the range of 35-65 nm. The synthesized nanoparticles showed different morphologies, such as spheres, triangles and hexagons (Figure 3b). The EDS spectrum of the modified composite film showed a well-defined peak corresponding to silver, indicating the existence of this element on the modified SS/PVA film (Figure 3c). The carbon, nitrogen, oxygen and chlorine peaks were attributed to sericin, PVA and PDA. The XRD patterns of sericin, SS/PVA film, PDA-SS/PVA film and AgNPs-modified PDA-SS/PVA film were shown in Figure $3 \mathrm{~d}$. A broad peak located at $2 \theta=19.2^{\circ}$ was observed in the sericin pattern, which was consistent with a previous report [49]. A characteristic broad peak located at $2 \theta=19.8^{\circ}$ was observed in the other XRD patterns, which may be attributed to the crystalline diffraction of PVA. No significant change was observed on the peaks after PDA coating, suggesting that PDA coating did not affect the crystal structure of SS/PVA composite film. For the AgNPs-modified PDA-SS/PVA film, four more peaks were observed at $2 \theta=38.12^{\circ}, 44.33^{\circ}, 64.46^{\circ}$ and $77.41^{\circ}$, which could be assigned to the crystal planes (111), (200), (220) and (311) of the face-centered cubic structure of the synthesized AgNPs, respectively [50,51].
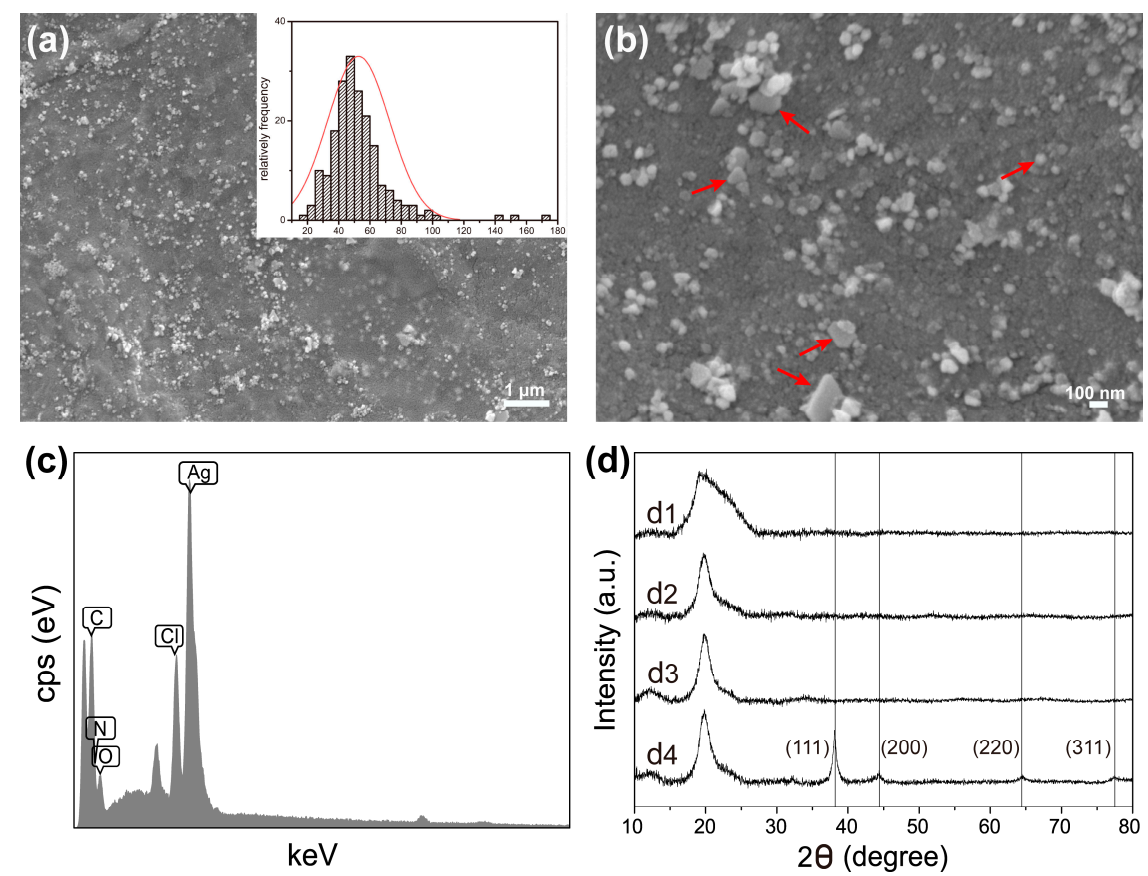

Figure 3. Field emission scanning electron microscope images of AgNPs-modified PDA-SS/PVA film (a) and (b). Inset in (a), particle size distribution of AgNPs. The red arrows in (b) indicated the different morphologies of the synthesized AgNPs. (c) EDS spectrum of a selected area of AgNPs-PDA-SS/PVA film. (d) XRD patterns of pure sericin (d1), SS/PVA film (d2), PDA-SS/PVA film (d3) and AgNPs modified PDA-SS/PVA film (d4). 
The results suggested that the synthesized AgNPs formed good crystalline structures. The high-density, good crystallinity and uniform distribution of AgNPs should greatly enhance the antibacterial activity of SS/PVA film.

\subsection{FT-IR Analysis}

The structures of sericin, SS/PVA composite film, PDA-SS/PVA composite film and AgNPs-modified PDA-SS/PVA composite film were characterized by fourier transform infrared spectroscopy. As shown in Figure 4, three characteristic peaks located at 1636, 1518 and $1244 \mathrm{~cm}^{-1}$ were observed in all the FT-IR spectra, corresponding to the amide I, II and III bands of sericin, respectively [52]. After PDA coating, two more weak peaks were observed at 1608 and $1503 \mathrm{~cm}^{-1}$. The former could be attributed to the $\mathrm{C}=\mathrm{C}$ stretching and $\mathrm{N}-\mathrm{H}$ deformation vibration of the indole or indoline structures in PDA [53]. The latter may be due to the skeletal vibrations of the PDA benzene ring [54]. The result indicated that PDA was successfully coated on the surface of SS/PVA film, which was in line with the SEM test results. PDA coating and AgNPs modification had no effect on the amide peaks of sericin, indicating these processes did not affect the structure of the SS/PVA film.

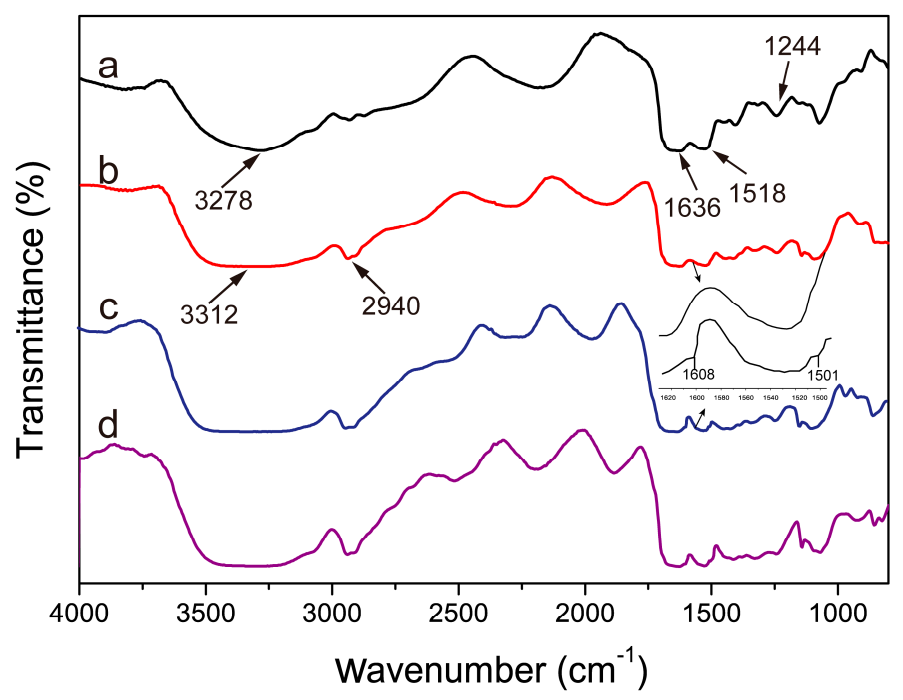

Figure 4. FT-IR spectra of pure sericin (a), SS/PVA composite film (b), PDA-SS/PVA composite film (c) and AgNPs-modified PDA-SS/PVA composite film (d).

\subsection{Wettability and Water Uptake Ability Measurements}

The water contact angles of SS/PVA, PDA-SS/PVA and AgNPs-PDA-SS/PVA films were shown in Figure 5a-c, respectively. The results showed the water contact angle of SS/PVA film was $27.6^{\circ}$, suggesting it was highly hydrophilic. The water contact angle of PDA-SS/PVA film was $43.5^{\circ}$, indicating the surface of PDA-SS/PVA film was hydrophilic. After AgNP modification, the water contact angle increased to $65.6^{\circ}$, meaning the surface still kept a certain degree of hydrophilicity. This may be due to the fact most of the surface hydrophilic groups were covered by the evenly distributed AgNPs.

To determine the water absorption of the prepared films, the swelling property of these films were analyzed, as shown in Figure 5d. The swelling ratios of SS/PVA and PDA-SS/PVA films were about twice as large as the control after the samples were immersed in PBS buffer ( $\mathrm{pH} 7.4$ ) for $12 \mathrm{~h}, 24 \mathrm{~h}$ and $48 \mathrm{~h}$, indicating these films had a better hygroscopicity. The swelling ratio of AgNPs-PDA-SS/PVA film was about 1.2 times of the control, suggesting AgNPs-PDA-SS/PVA film had good hygroscopicity. The effect of AgNPs modification on the SS/PVA film may be attributed to the hydrophilic sites being massively occupied by AgNPs. The swelling ratios did not change significantly with increased time. The reason may be the total surface area of the two-dimensional film interacted with water molecules 
during the initial swelling stage. The results suggested that AgNPs-modified PDA-SS/PVA film had good hydrophilicity and hygroscopicity, which may be useful in the field of wound dressings to maintain the wetness of the wound and reduce secondary damage.

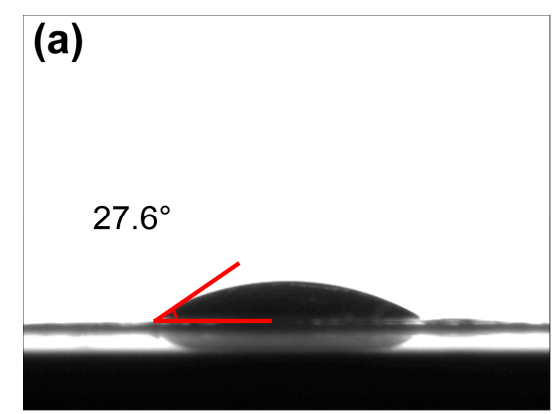

\section{(b)}
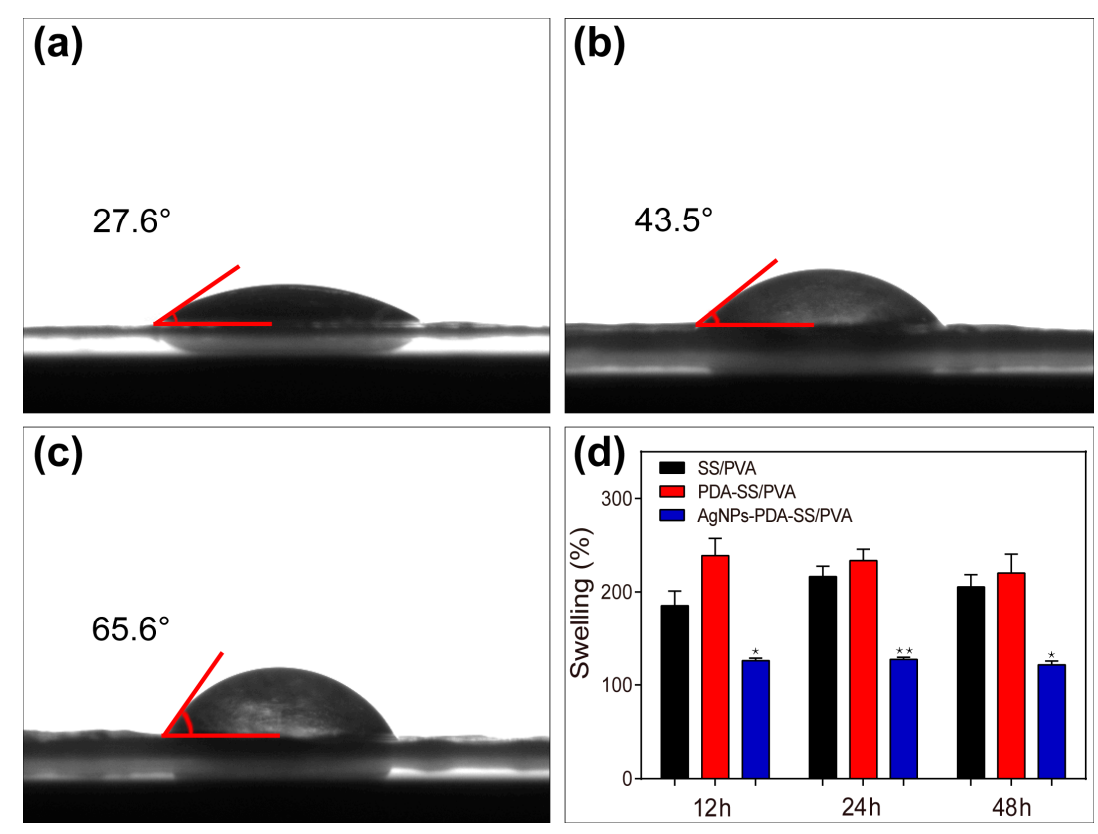

Figure 5. Water contact angles of SS/PVA (a), PDA-SS/PVA (b), and AgNPs-PDA-SS/PVA (c). Swelling ratio of these films (d) $(n=3$ per group; * indicates significant differences compared with SS /PVA film at $p<0.05,{ }^{* *}$ indicates significant differences compared with SS/PVA film at $p<0.01$ ).

\subsection{Mechanical Properties}

The tensile strength and elongation at break of SS/PVA, PDA-SS/PVA and AgNPs-PDA-SS/PVA films were shown in Figure 6. Tensile testing showed that PDA-SS/PVA and AgNPs-PDA-SS/PVA films exhibited a higher tensile strength compared to SS/PVA film. The enhancement of tensile strength may be attributed to the increase of film thickness after surface modification with AgNPs. The elongation value at break represents the flexibility of the film [55]. After PDA coating and AgNPs modification, no significant changes were observed in the elongation at break. These results indicated that AgNPs-PDA-SS/PVA film was stronger and tougher than SS/PVA film, which may have a potential application in biomedical materials such as wound dressing and skin replacement, since it had a typical tensile strength in the range of 2.5-16 Mpa [56-58].
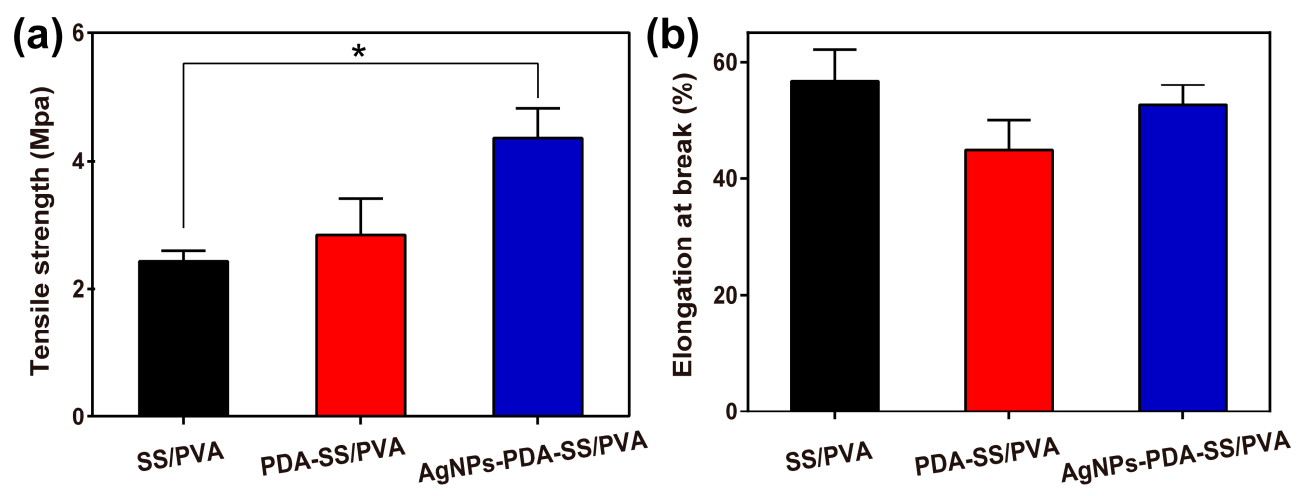

Figure 6. Mechanical properties of the films: (a) tensile strength and $(\mathbf{b})$ elongation at break $(\mathrm{n}=3$ per group; ${ }^{*}$ indicates $\left.p<0.05\right)$. 


\subsection{Inhibition Zone Assays}

The anti-bactericidal activities of SS/PVA, PDA-SS/PVA and AgNPs-PDA-SS/PVA films were evaluated against Gram-negative bacteria (E. coli) and Gram-positive bacteria (S. aureus), respectively. As shown in Figure 7, no significant inhibition zones were observed for SS/PVA and PDA-SS/PVA films. However, after AgNP modification, the film could efficiently kill the surrounding microbes, and form evident inhibition zones, indicating the antibacterial activity of the film depended on the presence of AgNPs. The diameters of the inhibition zones were summarized in Table 1. It was noted that the inhibition effect of AgNPs-PDA-SS/PVA film against Gram-positive bacteria was not as significant as that against Gram-negative bacteria, which may be due to the fact that Gram-positive bacteria is encased in a plasma membrane covered with a thick layer of peptidoglycan (about 20-80 nm) that limits the penetration of silver nanoparticles [59]. The result suggested the prepared AgNPs-PDA-SS/PVA film significantly inhibited the growth of E. coli (a) or S. aureus (b).
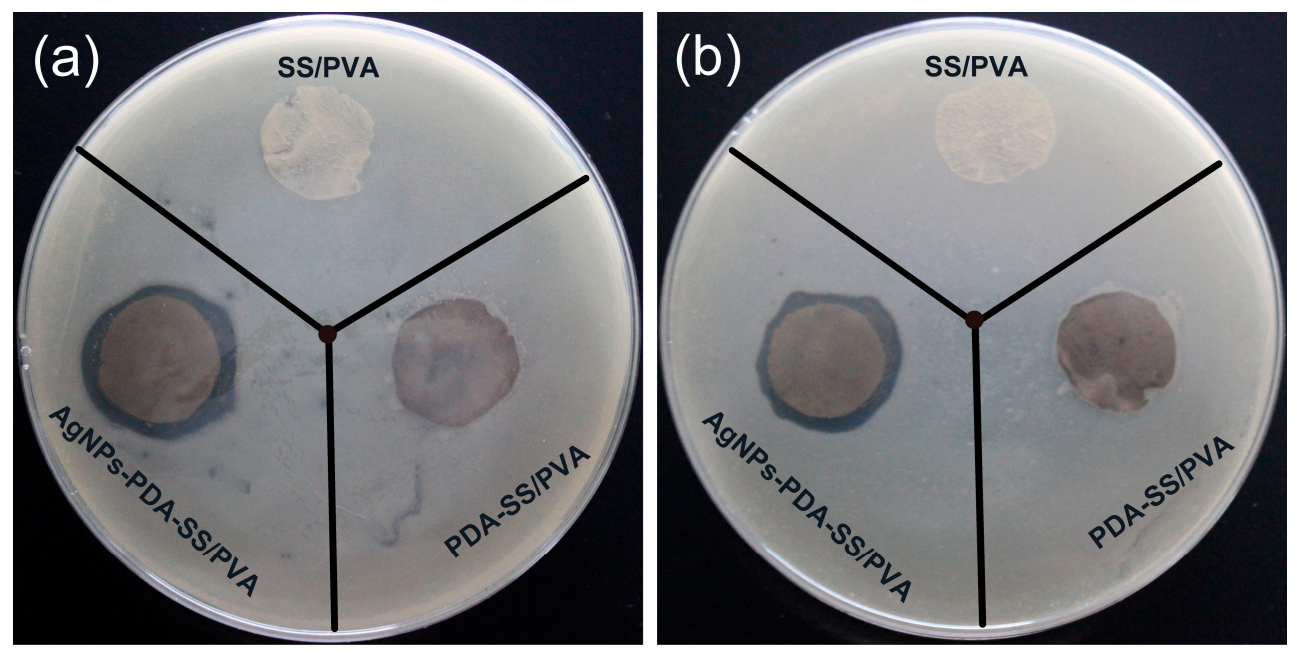

Figure 7. Inhibition zone assays of SS/PVA, PDA-SS/PVA, AgNPs-PDA-SS/PVA against E. coli (a) and S. aureus (b).

Table 1. Diameters of inhibition zones of PDA-SS/PVA film and AgNPs-PDA-SS/PVA film against E. coli and S. aureus.

\begin{tabular}{cccc}
\hline Bacteria & Control $(\mathbf{c m})$ & PDA-SS/PVA $(\mathbf{c m})$ & AgNPs-PDA-SS/PVA (cm) \\
\hline E. coil & $1.55 \pm 0.10$ & $1.65 \pm 0.11$ & $2.03 \pm 0.08$ \\
S. aureus & $1.55 \pm 0.15$ & $1.62 \pm 0.06$ & $1.86 \pm 0.06$ \\
\hline
\end{tabular}

\subsection{Bacterial Growth Curve}

To further evaluate the antimicrobial ability of AgNPs-PDA-SS/PVA film, the bacterial growth curves were analyzed by measuring the optical density (OD) of bacteria at $600 \mathrm{~nm}$, as shown in Figure 8a, b. SS/PVA and PDA-SS/PVA films showed negligible antibacterial activity against E. coli and $S$. aureus compared with the control. However, after AgNP modification on the surface of SS/PVA film, the lag phase of E. coli and S. aureus was significantly prolonged to $14 \mathrm{~h}$ and $12 \mathrm{~h}$, respectively. The result indicated AgNPs-PDA-SS/PVA film had good bacteria-killing and bacterial infection-inhibiting ability. The inhibitory effect of AgNPs-PDA-SS/PVA film against Gram-positive bacteria was less than that against Gram-negative bacteria, which was in good agreement with the inhibition zone assay results. It was noted that the bacterial growth could recover after $14 \mathrm{~h}$ or $12 \mathrm{~h}$, which may be attributed to the adaptability of bacteria to $\mathrm{Ag}^{+}$. In the real world, the bacteria growth conditions are relatively poor, hence, the prepared AgNPs-PDA-SS/PVA film may show better performance in antibacterial biomedicine applications. 


\subsection{Long-term Antimicrobial Stability Analyze}

To valuate the long-term antimicrobial stability, the antimicrobial activities of AgNPs-PDA-SS/PVA film against E. coli and S. aureus after treatment with different $\mathrm{pH}$ solutions for $24 \mathrm{~h}$ were measured. As shown in Figure 8c, d, even after $9 \mathrm{~h}$ had passed, AgNPs-PDA-SS/PVA film still showed a strong antibacterial activity compared to the control, especially under acidic conditions. The reason may be attributed rather to the passivation of AgNPs. The polymer film is more stable under acidic conditions than that under other conditions, which reduces the loss of AgNPs. The result indicated that AgNPs were stable and AgNPs-PDA-SS/PVA film had a long-term and stable antibacterial activity.
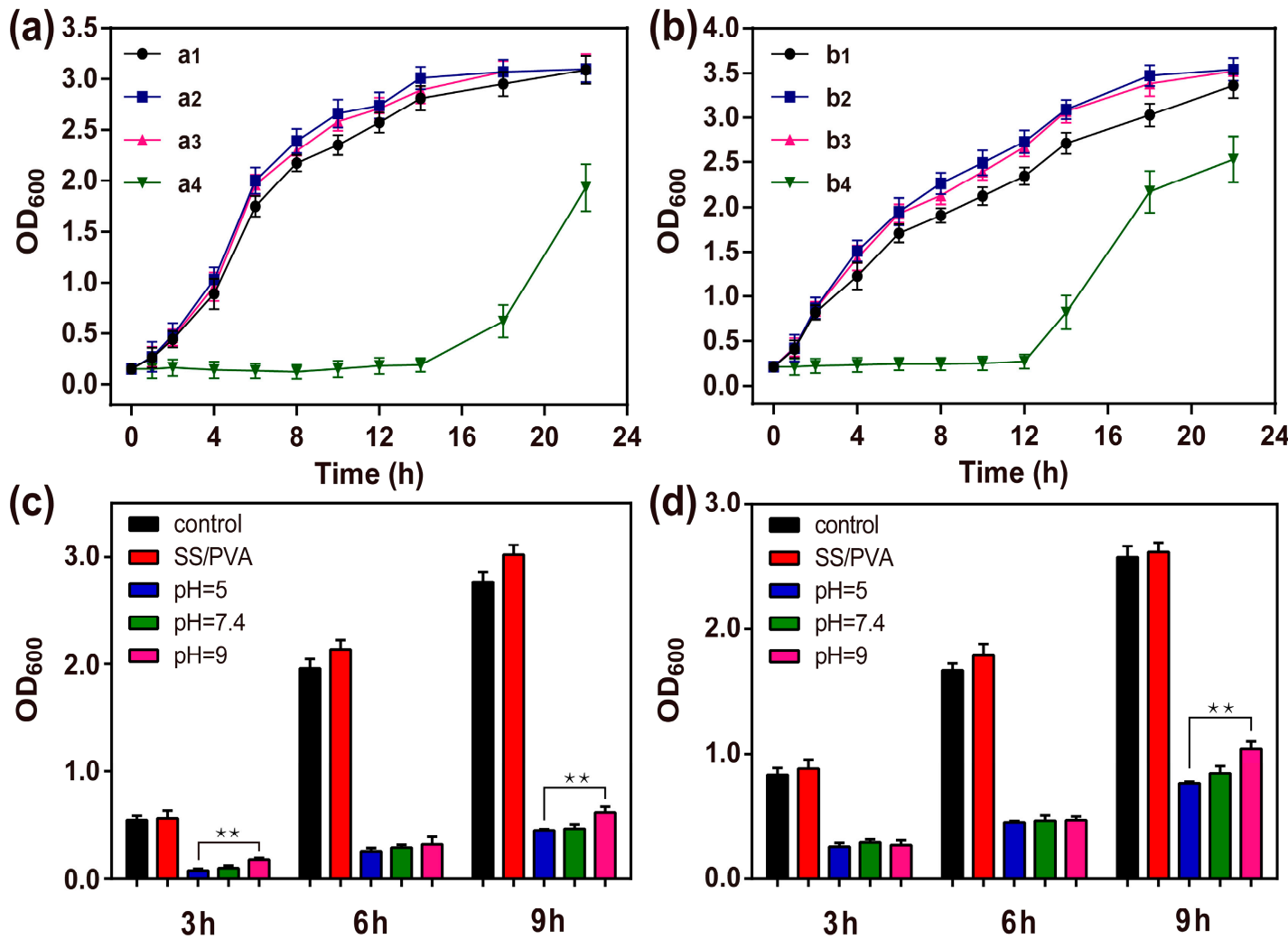

Figure 8. Growth curves of E. coli (a) and S. aureus (b). Bacteria without treatment (a1, b1); Bacteria treated with SS/PVA films (a2, b2), PDA-SS/PVA films (a3, b3) and AgNPs-PDA-SS/PVA films (a4, b4). Long-term bactericidal activity against $E$. coli $(\mathbf{c})$ and S. aureus $(\mathbf{d})\left(\mathrm{n}=3\right.$ per group; ${ }^{* *}$ indicates $\left.p<0.01\right)$.

\subsection{Mass Loss Studies}

The stability of wound dressing is directly related to its performance. To assess the potential of AgNPs-PDA-SS/PVA film as a wound dressing, we investigated the stability of AgNPs-PDA-SS/ PVA films at different $\mathrm{pH}$ values. The mass losses of the films at $\mathrm{pH} 4,7.4$ and 10 were shown in Figure 9. The results showed that the mass loss increased with time. Under alkaline conditions ( $\mathrm{pH} 10)$, the mass loss of AgNPs-PDA-SS/PVA film was about 71\% after 90 days of treatment. Under neutral conditions ( $\mathrm{pH} 7.4$ ), the mass loss was about 50\%. Under acidic conditions ( $\mathrm{pH} 4$ ), approximately $46 \%$ of the weight was lost. It was noted the mass loss of AgNPs-PDA-SS/PVA film under alkaline conditions was faster than that under an acidic or a neutral condition. This may be because in sericin the content of acidic amino acids (Glu and Asp, 24\%) was higher than that of alkaline amino acids (Lys, His and Arg, 8\%) [60], and the isoelectric point of sericin is approximately 3.8 [61]. In addition, PVA shows weak acidity in water. The result suggested that AgNPs-PDA-SS/PVA films had good stability and were environmentally friendly, because the film could be slowly degraded in a wet environment. 


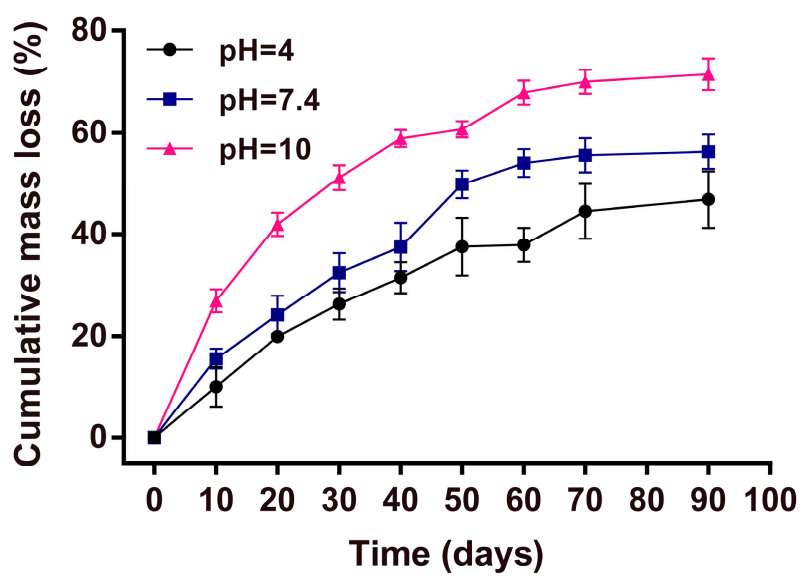

Figure 9. Mass loss kinetics of AgNPs-PDA-SS/PVA films at different $\mathrm{pH}$ values.

\section{Materials and Methods}

\subsection{Materials}

Silkworm cocoons were supplied by the State Key Laboratory of Silkworm Genome Biology, Southwest University (Beibei, Chongqing, China). Dopamine hydrochloride and silver nitrate $\left(\mathrm{AgNO}_{3}\right.$, AR, 99.99\%) were purchased from Aladdin Corp. (Shanghai, China). Tris(hydroxymethyl)aminomethane (Tris) and hydrochloric acid $(\mathrm{HCl})$ were purchased from Sangon Biotech (Shanghai, China). MiliQ water made by a MilliQ water purification system (Millipore, Billerica, MA, USA) was used in the experiments.

\subsection{Preparation of AgNPs Modified PDA-SS/PVA Composite Film}

Sericin was extracted from silk cocoons according to a previously reported procedure with minor modifications [62]. PVA was dissolved under a constant stirring speed at $80^{\circ} \mathrm{C}$ until it was fully dissolved to a final concentration of $5 \%(w / t)$. Then $4 \%(w / t)$ sericin solution and $5 \%(w / t)$ PVA solution were mixed together with a $1: 1$ ratio at $60^{\circ} \mathrm{C}$ for at least $30 \mathrm{~min}$, and then frozen under $-20{ }^{\circ} \mathrm{C}$ and thawed at room temperature for four cycles to form a SS/PVA hydrogel. The hydrogel became SS/PVA blend film upon drying. Dopamine powder was dissolved in Tris- $\mathrm{HCl}$ buffer to formulate different concentrations $(0.5,1.0,2.0,3.0$ and $5.0 \mathrm{mg} / \mathrm{mL})$, and then adjusted to $\mathrm{pH} 8.5$. SS/PVA films were immersed directly into the freshly prepared dopamine solutions for $12 \mathrm{~h}$ with continuously magnetic stirring at $37^{\circ} \mathrm{C}$. Then the PDA coated SS/PVA films were taken out and rinsed with MiliQ water until the washing water became clear. Furthermore, the prepared films were dried at room temperature and then soaked in $30 \mathrm{mM} \mathrm{AgNO}_{3}$ at room temperature for $12 \mathrm{~h}$. Finally, the AgNPs modified PDA-SS/PVA composite films were produced after repeated washing and drying at room temperature.

\subsection{Materials Characterization}

The morphologies of PDA-SS/PVA film and AgNPs modified PDA-SS/PVA film were imaged on a JCM-5000 SEM instrument (JEOL, Tokyo, Japan). At the same time, energy-dispersive X-ray spectroscopy (EDS) (INCA X-Max 250, Oxford, England) were collected to analyze the chemical elements in these samples. The modified and unmodified AgNPs SS/PVA films were measured on an $X^{\prime}$ Pert Powder XRD with a $2 \theta$ range of $10^{\circ}$ to $80^{\circ}$ (PANalytical, Almelo, The Netherlands). FT-IR measurements were performed in the wavenumber of $4000-800 \mathrm{~cm}^{-1}$ with $2 \mathrm{~cm}^{-1}$ resolution on a Nicolet iz10 FT-IR spectrometer (ThermoFisher Scientific Corp, Waltham, MA, USA). 


\subsection{Wettability Measurement}

The wettabilities of the samples were measured via sessile drop contact angle measurements on a KRÜSSDSA100 contact angle system (Krüss, Hamburg, Germany) at room temperature. A sample was examined in five different positions. A water droplet of $4 \mu \mathrm{L}$ was dropped on the surface of the sample, and then the contact angle was measured.

\subsection{Water Uptake Ability}

The swelling property of the composite film in water was investigated by the gravimetric method developed by Mandal et al. [63] with a minor modification. The dried composite films were weighed as $W_{1}$ and immersed into $10 \mathrm{~mL}$ water at $37^{\circ} \mathrm{C}$. At various time intervals, the films were taken out, and extra water on the surface of the films was carefully removed with filter paper, then weighed as $W_{2}$ immediately. The swelling ratio $(S)$ was calculated according to the following equation:

$$
S(\%)=\left(W_{2}-W_{1}\right) \times 100 \% / W_{1}
$$

At least three repeats were performed for each film under the same condition and the average value was used to evaluate the swellability of the prepared films.

\subsection{Mechanical Analysis}

The mechanical property of composite film was measured on an AG-Xplus universal testing machine (Shimadzu, Kyoto, Japan) equipped with a 1000-N load cell at a crosshead speed of $3 \mathrm{~mm} / \mathrm{min}$. Each composite film was tested with a dimension of $4 \mathrm{~cm} \times 1 \mathrm{~cm}$ (length $\times$ width). The thickness of the composite film was determined by SEM. The raw data were transformed into true stress $(\sigma)$ and strain $(\varepsilon)$ to plot the stress-strain curves [64].

\subsection{Inhibition Zone Assay}

The inhibition zone assay was performed according to the method described by Schillinger and Lucke [65]. E. coli and S. aureus were inoculated into $100 \mathrm{~mL} \mathrm{LB}$ medium (pH 7.4) at $37^{\circ} \mathrm{C}$ under a constant shaking speed of $220 \mathrm{rpm}$. Bacteria at lag phase were applied to agar medium plates in the presence of circular AgNPs modified or unmodified sericin composite films $(\mathrm{d}=1.50 \mathrm{~cm})$. After incubation at $37^{\circ} \mathrm{C}$ overnight, the antibacterial activities of the samples were evaluated according to the diameters of bacterial inhibition zones.

\subsection{Growth Curve Assay}

The bacterial growth curve assay was carried out according to Pal's protocol [66]. Bacteria at lag phase were inoculated into $10 \mathrm{~mL}$ LB medium ( $\mathrm{pH}$ 7.4) and cultured under a constant shaking speed of $220 \mathrm{rpm}$ at $37^{\circ} \mathrm{C}$ in the presence of AgNPs modified or unmodified SS/PVA blend films $(1 \mathrm{~cm} \times 1 \mathrm{~cm})$. About $0.5 \mathrm{~mL}$ bacterial suspensions were collected at different time intervals to measure the optical density of bacteria at $600 \mathrm{~nm}\left(\mathrm{OD}_{600}\right)$. All growth curve tests were made in triplicate to ensure the reproducibility of the tests.

\subsection{Long-Term Antimicrobial Stability Test}

For long-term antimicrobial stability test, AgNPs-modified PDA-SS/PVA films $(1 \mathrm{~cm} \times 1 \mathrm{~cm})$ were immersed in PBS buffer with different $\mathrm{pH}(5,7.4$ or 9$)$ for $24 \mathrm{~h}$, respectively. SS/PVA blend film treated with bacterial was set as a positive control. At various time intervals, the antimicrobial activity test was performed against $S$. aureus and E. coli using the previously described method. 


\subsection{Mass Loss Test}

The AgNPs-modified sericin composite films $(3 \mathrm{~cm} \times 3 \mathrm{~cm})$ were soaked into PBS with different $\mathrm{pH}$ values $(4,7.4,10)$ at $37^{\circ} \mathrm{C}$. PBS was replaced daily. At given time points, the films were taken out, washed, lyophilized, and weighed. The mass loss ratio was calculated as the difference between the initial and following dry masses at indicated times divided by the initial dry mass.

\subsection{Statistics}

All experiments were performed in triplicate, and data were presented as the means \pm SD. The statistical significance was determined by paired and unpaired Student's $t$-tests together with ANOVA $\left({ }^{*} p<0.05, * * p<0.01\right)$.

\section{Conclusions}

In this study, we have developed a one-step method to prepare AgNPs-PDA-SS/PVA film without the introduction of additional reduction reagents. High-density AgNPs are synthesized on the surface of SS/PVA film via the adsorption and direct reduction of PDA. The synthesized AgNPs are evenly distributed and have good crystallinity. The PDA coating and AgNPs modification do not alter the structure of the SS/PVA film. The prepared AgNPs-PDA-SS/PVA film has good hydrophilicity, hygroscopicity, and mechanical performance. More importantly, it has a long-term stable antibacterial activity against both Gram-negative and Gram-positive bacteria. In addition, the film has good stability and is environmentally friendly. This film with various excellent performances is expected to be useful in biomaterial applications such as wound dressings. Furthermore, a simple procedure is proposed to introduce dopamine coating on film preparations, which will facilitate the fabrication of more dopamine-containing compound films or nanofilms, which may be a productive research area in the future.

Acknowledgments: This work was supported by State Key Program of National Natural Science of China (No. 31530071), National Natural Science Foundation of China (No. 31572465, 31402139), Chongqing Research Program of Basic Research and Frontier Technology (cstc2015jcyjA00040, cstc2015jcyjBX0035), Fundamental Research Funds for the Central Universities (No. XDJK2013A019), Graduate Research and Innovation Project of Chongqing (No. CYS16074), Open Project Program of Chongqing Engineering and Technology Research Center for Novel Silk Materials (silkgczx2016003), Start-up Grant from Southwest University (SWU112111) and Chongqing Eyas Program for Young Creative Talents (CY160205).

Author Contributions: Rui Cai conceived, designed and performed the experiments, and wrote the initial manuscript draft; Rui Cai and Gang Tao analyzed the data and revised the manuscript draft; Wenchao Jiang and Kai Song assisted the experiments; Hua Zuo and Huawei He assisted the format of manuscript draft; Yejing Wang supervised the research and revised the manuscript.

Conflicts of Interest: The authors declare that they have no competing interests, including specific financial interests and relationships and affiliations relevant to the subject of this manuscript.

\section{References}

1. Zhang, Y.Q.; Tao, M.L.; Shen, W.D.; Zhou, Y.Z.; Ding, Y.; Ma, Y.; Zhou, W.L. Immobilization of l-asparaginase on the microparticles of the natural silk sericin protein and its characters. Biomaterials 2004, 25, 3751-3759. [CrossRef] [PubMed]

2. Takasu, Y.; Yamada, H.; Tsubouchi, K. Isolation of three main sericin components from the cocoon of the silkworm, Bombyx mori. Biosci. Biotech. Bioch. 2002, 66, 2715-2718. [CrossRef] [PubMed]

3. Padamwar, M.N.; Pawar, A.P. Silk sericin and its applications: A review. J. Sci. Ind. Res. India 2004, 63, 323-329.

4. Zhaorigetu, S.; Yanaka, N.; Sasaki, M.; Watanabe, H.; Kato, N. Inhibitory effects of silk protein, sericin on UVB-induced acute damage and tumor promotion by reducing oxidative stress in the skin of hairless mouse. J. Photochem. Photobiol. B 2003, 71, 11-17. [CrossRef]

5. Zhang, Y.Q. Applications of natural silk protein sericin in biomaterials. Biotechnol. Adv. 2002, 20, 91-100. [CrossRef] 
6. Cho, K.Y.; Moon, J.Y.; Lee, Y.W.; Lee, K.G.; Yeo, J.H.; Kweon, H.Y.; Kim, K.H.; Cho, C.S. Preparation of self-assembled silk sericin nanoparticles. Int. J. Biol. Macromol. 2003, 32, 36-42. [CrossRef]

7. Dash, B.C.; Mandal, B.B.; Kundu, S.C. Silk gland sericin protein membranes: Fabrication and characterization for potential biotechnological applications. J. Biotechnol. 2009, 144, 321-329. [CrossRef] [PubMed]

8. Mandal, B.B.; Priya, A.S.; Kundu, S.C. Novel silk sericin/gelatin 3-d scaffolds and 2-d films: Fabrication and characterization for potential tissue engineering applications. Acta Biomater. 2009, 5, 3007-3020. [CrossRef] [PubMed]

9. Siritientong, T.; Srichana, T.; Aramwit, P. The effect of sterilization methods on the physical properties of silk sericin scaffolds. Aaps PharmSciTech 2011, 12, 771-781. [CrossRef] [PubMed]

10. Aramwit, P.; Sangcakul, A. The effects of sericin cream on wound healing in rats. Biosci. Biotechnol. Biochem. 2007, 71, 2473-2477. [CrossRef]

11. Aramwit, P.; Kanokpanont, S.; De-Eknamkul, W.; Srichana, T. Monitoring of inflammatory mediators induced by silk sericin. J. Biosci. Bioeng. 2009, 107, 556-561. [CrossRef] [PubMed]

12. Martinez-Mora, C.; Mrowiec, A.; Garcia-Vizcaino, E.M.; Alcaraz, A.; Cenis, J.L.; Nicolas, F.J. Fibroin and sericin from Bombyx mori silk stimulate cell migration through upregulation and phosphorylation of c-jun. PLoS ONE 2012, 7, e42271. [CrossRef] [PubMed]

13. Greaves, N.S.; Ashcroft, K.J.; Baguneid, M.; Bayat, A. Current understanding of molecular and cellular mechanisms in fibroplasia and angiogenesis during acute wound healing. J. Dermatol. Sci. 2013, 72, $206-217$. [CrossRef] [PubMed]

14. Aramwit, P.; Palapinyo, S.; Srichana, T.; Chottanapund, S.; Muangman, P. Silk sericin ameliorates wound healing and its clinical efficacy in burn wounds. Arch. Dermatol. Res. 2013, 305, 585-594. [CrossRef] [PubMed]

15. Dash, R.; Ghosh, S.K.; Kaplan, D.L.; Kundu, S.C. Purification and biochemical characterization of a $70 \mathrm{kDa}$ sericin from tropical tasar silkworm, Antheraea mylitta. Comp. Biochem. Phys. B 2007, 147, 129-134. [CrossRef] [PubMed]

16. Oh, H.; Lee, J.Y.; Kim, M.K.; Um, I.C.; Lee, K.H. Refining hot-water extracted silk sericin by ethanol-induced precipitation. Int. J. Biol. Macromol. 2011, 48, 32-37. [CrossRef] [PubMed]

17. Nayak, S.; Talukdar, S.; Kundu, S.C. Potential of 2D crosslinked sericin membranes with improved biostability for skin tissue engineering. Cell Tissue Res. 2012, 347, 783-794. [CrossRef] [PubMed]

18. Zhang, X.H.; Tsukada, M.; Morikawa, H.; Aojima, K.; Zhang, G.Y.; Miura, M. Production of silk sericin/silk fibroin blend nanofibers. Nanoscale Res. Lett. 2011, 6, 510. [CrossRef] [PubMed]

19. Liu, Q.; Qiu, G.; Zhou, Z.; Li, J.; Amy, G.L.; Xie, J.; Lee, J.Y. An effective design of electrically conducting thin-film composite (TFC) membranes for bio and organic fouling control in forward osmosis (FO). Environ. Sci. Technol. 2016, 50, 10596-10605. [CrossRef] [PubMed]

20. Feng, Q.L.; Wu, J.; Chen, G.Q.; Cui, F.Z.; Kim, T.N.; Kim, J.O. A mechanistic study of the antibacterial effect of silver ions on Escherichia coli and Staphylococcus aureus. J. Biomed. Mater. Res. 2000, 52, 662-668. [CrossRef]

21. Jung, W.K.; Koo, H.C.; Kim, K.W.; Shin, S.; Kim, S.H.; Park, Y.H. Antibacterial activity and mechanism of action of the silver ion in Staphylococcus aureus and Escherichia coli. Appl. Environ. Microb. 2008, 74, 2171-2178. [CrossRef] [PubMed]

22. Tao, G.; Wang, Y.J.; Liu, L.N.; Chang, H.P.; Zhao, P.; He, H.W. Preparation and characterization of silver nanoparticles composited on polyelectrolyte film coated sericin gel for enhanced antibacterial application. Sci. Adv. Mater. 2016, 8, 1547-1552. [CrossRef]

23. Lara, H.H.; Garza-Trevino, E.N.; Ixtepan-Turrent, L.; Singh, D.K. Silver nanoparticles are broad-spectrum bactericidal and virucidal compounds. J. Nanobiotechnol. 2011, 9, 30. [CrossRef] [PubMed]

24. Franci, G.; Falanga, A.; Galdiero, S.; Palomba, L.; Rai, M.; Morelli, G.; Galdiero, M. Silver nanoparticles as potential antibacterial agents. Molecules 2015, 20, 8856-8874. [CrossRef] [PubMed]

25. Sanpui, P.; Murugadoss, A.; Prasad, P.D.; Ghosh, S.S.; Chattopadhyay, A. The antibacterial properties of a novel chitosan-Ag-nanoparticle composite. Int. J. Food Microbiol. 2008, 124, 142-146. [CrossRef] [PubMed]

26. Lyutakov, O.; Hejna, O.; Solovyev, A.; Kalachyova, Y.; Svorcik, V. Polymethylmethacrylate doped with porphyrin and silver nanoparticles as light-activated antimicrobial material. RSC Adv. 2014, 4, 50624-50630. [CrossRef] 
27. Skladanowski, M.; Golinska, P.; Rudnicka, K.; Dahm, H.; Rai, M. Evaluation of cytotoxicity, immune compatibility and antibacterial activity of biogenic silver nanoparticles. Med. Microbiol. Immun. 2016, 205, 603-613. [CrossRef] [PubMed]

28. Panacek, A.; Smekalova, M.; Kilianova, M.; Prucek, R.; Bogdanova, K.; Vecerova, R.; Kolar, M.; Havrdova, M.; Plaza, G.A.; Chojniak, J.; et al. Strong and nonspecific synergistic antibacterial efficiency of antibiotics combined with silver nanoparticles at very low concentrations showing no cytotoxic effect. Molecules 2016, $21,26$.

29. Elliott, C. The effects of silver dressings on chronic and burns wound healing. Br. J. Nurs. 2010, 19, 32-36. [CrossRef] [PubMed]

30. Zheng, K.; Setyawati, M.I.; Lim, T.-P.; Leong, D.T.; Xie, J. Antimicrobial cluster bombs: Silver nanoclusters packed with daptomycin. ACS Nano 2016, 10, 7934-7942. [CrossRef] [PubMed]

31. Slepička, P.; Malá, Z.; Rimpelová, S.; Švorčík, V. Antibacterial properties of modified biodegradable PHB non-woven fabric. Mater. Sci. Eng. C 2016, 65, 364-368. [CrossRef] [PubMed]

32. Babu, K.F.; Dhandapani, P.; Maruthamuthu, S.; Kulandainathan, M.A. One pot synthesis of polypyrrole silver nanocomposite on cotton fabrics for multifunctional property. Carbohyd. Polym. 2012, 90, 1557-1563. [CrossRef] [PubMed]

33. Swope, K.L.; Flicklinger, M.C. The use of confocal scanning laser microscopy and other tools to characterize Escherichia coli in a high-cell-density synthetic biofilm. Biotechnol. Bioeng. 1996, 52, 340-356. [CrossRef]

34. Lee, J.M.; Yu, J.E.; Koh, Y.S. Experimental study on the effect of wavelength in the laser cleaning of silver threads. J. Cult. Herit. 2003, 4, 157-161. [CrossRef]

35. Ma, Z.Y.; Jia, X.; Hu, J.M.; Liu, Z.Y.; Wang, H.Y.; Zhou, F. Mussel-inspired thermosensitive polydopamine-graft-poly( $\mathrm{N}$-isopropylacrylamide) coating for controlled-release fertilizer. J. Agric. Food Chem. 2013, 61, 12232-12237. [CrossRef] [PubMed]

36. Goswami, N.; Lin, F.; Liu, Y.; Leong, D.T.; Xie, J. Highly luminescent thiolated gold nanoclusters impregnated in nanogel. Chem. Mater. 2016, 28, 4009-4016. [CrossRef]

37. Chang, S.Q.; Kang, B.; Dai, Y.D.; Chen, D. Synthesis of antimicrobial silver nanoparticles on silk fibers via $\gamma$-radiation. J. Appl. Polym. Sci. 2009, 112, 2511-2515. [CrossRef]

38. Zhang, D.; Toh, G.W.; Lin, H.; Chen, Y. In situ synthesis of silver nanoparticles on silk fabric with PNP for antibacterial finishing. J. Mater. Sci. 2012, 47, 5721-5728. [CrossRef]

39. Zhang, A.; Neumeyer, J.L.; Baldessarini, R.J. Recent progress in development of dopamine receptor subtype-selective agents: Potential therapeutics for neurological and psychiatric disorders. Chem. Rev. 2007, 107, 274-302. [CrossRef] [PubMed]

40. Xi, Z.Y.; Xu, Y.Y.; Zhu, L.P.; Wang, Y.; Zhu, B.K. A facile method of surface modification for hydrophobic polymer membranes based on the adhesive behavior of poly(dopa) and poly(dopamine). J. Membr. Sci. 2009, 327, 244-253. [CrossRef]

41. Lee, H.; Dellatore, S.M.; Miller, W.M.; Messersmith, P.B. Mussel-inspired surface chemistry for multifunctional coatings. Science 2007, 318, 426-430. [CrossRef] [PubMed]

42. Postma, A.; Yan, Y.; Wang, Y.J.; Zelikin, A.N.; Tjipto, E.; Caruso, F. Self-Polymerization of dopamine as a versatile and robust technique to prepare polymer capsules. Chem. Mater. 2009, 21, 3042-3044. [CrossRef]

43. Ye, Q.; Zhou, F.; Liu, W.M. Bioinspired catecholic chemistry for surface modification. Chem. Soc. Rev. 2011, 40, 4244-4258. [CrossRef] [PubMed]

44. Fan, K.W.; Granville, A.M. Surface property modification of silver nanoparticles with dopamine-functionalized poly(pentafluorostyrene) via raft polymerization. Polymers 2016, 8, 81. [CrossRef]

45. Zhang, Z.; Zhang, J.; Zhang, B.L.; Tang, J.L. Mussel-Inspired functionalization of graphene for synthesizing Ag-polydopamine-graphene nanosheets as antibacterial materials. Nanoscale 2013, 5, 118-123. [CrossRef] [PubMed]

46. GhavamiNejad, A.; Aguilar, L.E.; Ambade, R.B.; Lee, S.-H.; Park, C.H.; Kim, C.S. Immobilization of silver nanoparticles on electropolymerized polydopamine films for metal implant applications. Colloids Interface Sci. Commun. 2015, 6, 5-8. [CrossRef]

47. Zhou, P.; Deng, Y.; Lyu, B.; Zhang, R.R.; Zhang, H.; Ma, H.W.; Lyu, Y.L.; Wei, S.C. Rapidly-deposited polydopamine coating via high temperature and vigorous stirring: formation, characterization and biofunctional evaluation. PLoS ONE 2014, 9, e113087. [CrossRef] [PubMed] 
48. Ball, V.; Del Frari, D.; Toniazzo, V.; Ruch, D. Kinetics of polydopamine film deposition as a function of $\mathrm{pH}$ and dopamine concentration: insights in the polydopamine deposition mechanism. J. Colloid Interface Sci. 2012, 386, 366-372. [CrossRef] [PubMed]

49. Tao, G.; Liu, L.N.; Wang, Y.J.; Chang, H.P.; Zhao, P.; Zuo, H.; He, H.W. Characterization of silver nanoparticle in situ synthesis on porous sericin gel for antibacterial application. J. Nanomater. 2016, 2016, 1-8.

50. Abbasi, A.R.; Morsali, A. Synthesis and properties of silk yarn containing Ag nanoparticles under ultrasound irradiation. Ultrason. Sonochem. 2011, 18, 282-287. [CrossRef] [PubMed]

51. Feng, J.J.; Zhang, P.P.; Wang, A.J.; Liao, Q.C.; Xi, J.L.; Chen, J.R. One-Step synthesis of monodisperse polydopamine-coated silver core-shell nanostructures for enhanced photocatalysis. New J. Chem. 2012, 36, 148-154. [CrossRef]

52. Zhang, X.M.; Wyeth, P. Using FTIR spectroscopy to detect sericin on historic silk. Sci. China Chem. 2010, 53, 626-631. [CrossRef]

53. Dreyer, D.R.; Miller, D.J.; Freeman, B.D.; Paul, D.R.; Bielawski, C.W. Elucidating the structure of poly(dopamine). Langmuir 2012, 28, 6428-6435. [CrossRef] [PubMed]

54. Lu, Z.S.; Xiao, J.; Wang, Y.; Meng, M. In situ synthesis of silver nanoparticles uniformly distributed on polydopamine-coated silk fibers for antibacterial application. J. Colloid Interface Sci. 2015, 452, 8-14. [CrossRef] [PubMed]

55. Jin, Y.X.; Deng, D.Y.; Cheng, Y.R.; Kong, L.Q.; Xiao, F. Annealing-Free and strongly adhesive silver nanowire networks with long-term reliability by introduction of a nonconductive and biocompatible polymer binder. Nanoscale 2014, 6, 4812-4818. [CrossRef] [PubMed]

56. Bahrami, S.B.; Kordestani, S.S.; Mirzadeh, H.; Mansoori, P. Poly(vinyl alcohol)-chitosan blends: preparation, mechanical and physical properties. Iran Polym. J. 2003, 12, 139-146.

57. Cervera, M.F.; Heinamaki, J.; Krogars, K.; Jorgensen, A.C.; Karjalainen, M.; Colarte, A.I.; Yliruusi, J. Solid-State and mechanical properties of aqueous chitosan-amylose starch films plasticized with polyols. Aaps PharmSciTech 2004, 5, 109.

58. Xu, F.; Wen, T.J.; Lu, T.J.; Seffen, K.A. Skin biothermomechanics for medical treatments. J. Mech. Behav. Biomed. 2008, 1, 172-187. [CrossRef] [PubMed]

59. Kumar, P.S.; Abhilash, S.; Manzoor, K.; Nair, S.; Tamura, H.; Jayakumar, R. Preparation and characterization of novel $\beta$-chitin/nanosilver composite scaffolds for wound dressing applications. Carbohyd. Polym. 2010, 80, 761-767. [CrossRef]

60. Tao, W.; Li, M.Z.; Xie, R.J. Preparation and structure of porous silk sericin materials. Macromol. Mater. Eng. 2005, 290, 188-194. [CrossRef]

61. Wang, Z.; Zhang, Y.S.; Zhang, J.X.; Huang, L.; Liu, J.; Li, Y.K.; Zhang, G.Z.; Kundu, S.C.; Wang, L. Exploring natural silk protein sericin for regenerative medicine: an injectable, photoluminescent, cell-adhesive 3D hydrogel. Sci. Rep. 2014, 4, 7064. [CrossRef] [PubMed]

62. Wu, J.H.; Wang, Z.; Xu, S.Y. Preparation and characterization of sericin powder extracted from silk industry wastewater. Food Chem. 2007, 103, 1255-1262. [CrossRef]

63. Vazquez, B.; Roman, J.S.; Peniche, C.; Cohen, M.E. Polymeric hydrophilic hydrogels with flexible hydrophobic chains. Control of the hydration and interactions with water molecules. Macromolecules 1997, 30, 8440-8446. [CrossRef]

64. Guan, J.; Porter, D.; Vollrath, F. Thermally induced changes in dynamic mechanical properties of native silks. Biomacromolecules 2013, 14, 930-937. [CrossRef] [PubMed]

65. Schillinger, U.; Lucke, F.K. Antibacterial activity of lactobacillus-sake isolated from meat. Appl. Environ. Microb. 1989, 55, 1901-1906.

66. Pal, S.; Tak, Y.K.; Song, J.M. Does the antibacterial activity of silver nanoparticles depend on the shape of the nanoparticle? A study of the gram-negative bacterium Escherichia coli. Appl. Environ. Microb. 2007, 73, 1712-1720. [CrossRef] [PubMed]

Sample Availability: Samples of the silk cocoons are available from the authors.

(C) 2017 by the authors. Licensee MDPI, Basel, Switzerland. This article is an open access article distributed under the terms and conditions of the Creative Commons Attribution (CC BY) license (http:/ / creativecommons.org/licenses/by/4.0/). 